\title{
Microseismic data - a comparison between routine trigger method and continuous data processing
}

\author{
M Salvoni Australian Centre for Geomechanics and The University of Western Australia, Australia \\ IG Morkel Australian Centre for Geomechanics and The University of Western Australia, Australia \\ PM Dight Australian Centre for Geomechanics and The University of Western Australia, Australia
}

\begin{abstract}
Over the years there have been several attempts to undertake routine real-time microseismic monitoring of open pit mine slopes. This technique has been commonly used in underground operations to manage induced seismicity and rockburst. However, the microseismic monitoring in open pits is still experimental and further studies are required. In this paper, we analysed the data from MMG Century mine where, in November 2013, a microseismic system was installed in order to monitor a large scale unstable slope. Design of the system and installation of the instruments were performed by the Institute of Mine Seismology. The seismic events were recorded, based both on a triggered scheme and in continuous mode. As part of our research project, data was given to four independent groups to be analysed and provide their own results. One group applied a routine method using the triggered data, manually processed them and made them available for the engineers on site within 10 minutes. The other three groups later reanalysed the data using both triggered and continuous waveform. Our work compared the different results obtained, and highlighted some of the key points engineers should be aware of in the design and implementation of a microseismic system in open pit mines.
\end{abstract}

\section{Introduction}

Century mine is an open pit mine owned and operated by MMG Limited. It is located near Lawn Hill in North Queensland, approximately $250 \mathrm{~km}$ northwest of Mount Isa, close to the Northern Territory border. The Century deposit represents one of the major sediment-hosted zinc, lead and silver deposits of the Mount Isa inlier and McArthur basin. The ultimate pit was approximately $2.5 \mathrm{~km}$ long by $1.5 \mathrm{~km}$ wide at the surface, with a final depth of $320 \mathrm{~m}$. After 16 years, mining operations ceased at the end of 2015 and the pit is currently in the mine closure phase, which may span over a period of 30 years.

Since commencement of mining in the South-West (SW) Wall in 2007, the area has represented an ongoing challenge for engineers on site, due to persistent stability problems. A brief history of the instabilities in the area, and the subsequent redesign and remediation work undertaken, are discussed in Hendersonhall et al. (2010) and Kurukuk and Sweeney (2012). The current pit wall is a $300 \mathrm{~m}$ high slope, with an overall angle of $40^{\circ}$ (Figure 1). It is developed within the footwall sequence and is dominated by the presence of thinly bedded shales (bedding space between 2 and $50 \mathrm{~cm}$ ). Within the footwall sequence two main geotechnical domains have been identified: lower footwall (LFW) and upper footwall (UFW). The LFW is dominated by low strength black carbonaceous shales, a tight and fair rock mass with bedding partings, continuous joints and occasional bedding shears. In comparison, the UFW comprises black laminated shales and a more competent rock mass with distinctive laminated bedding (Hendersonhall et al. 2010).

Pandora's Fault, a deposit scale major structure, represents the boundary between the UFW and LFW shale domains. It is a gently to moderately north dipping, east-west striking normal fault, which displaces the orebody into two major blocks. Pandora's Fault has been interpreted as a scissor fault, with displacement varying along the strike from zero at the eastern margin of the deposit to over $300 \mathrm{~m}$ at the western margin (Broadbent et al. 2002). However, in the SW corner, it displays a sharp change in orientation from a strike of east-west to northwest. The area is also characterised by the presence of a set of east-west, north 
dipping sub-vertical structures. One of those structures, known as Page Creek Fault, has contributed to the local rotation of bedding and joint sets, resulting in the formation of a highly sheared and fractured block (Kurukuk \& Sweeney 2012).

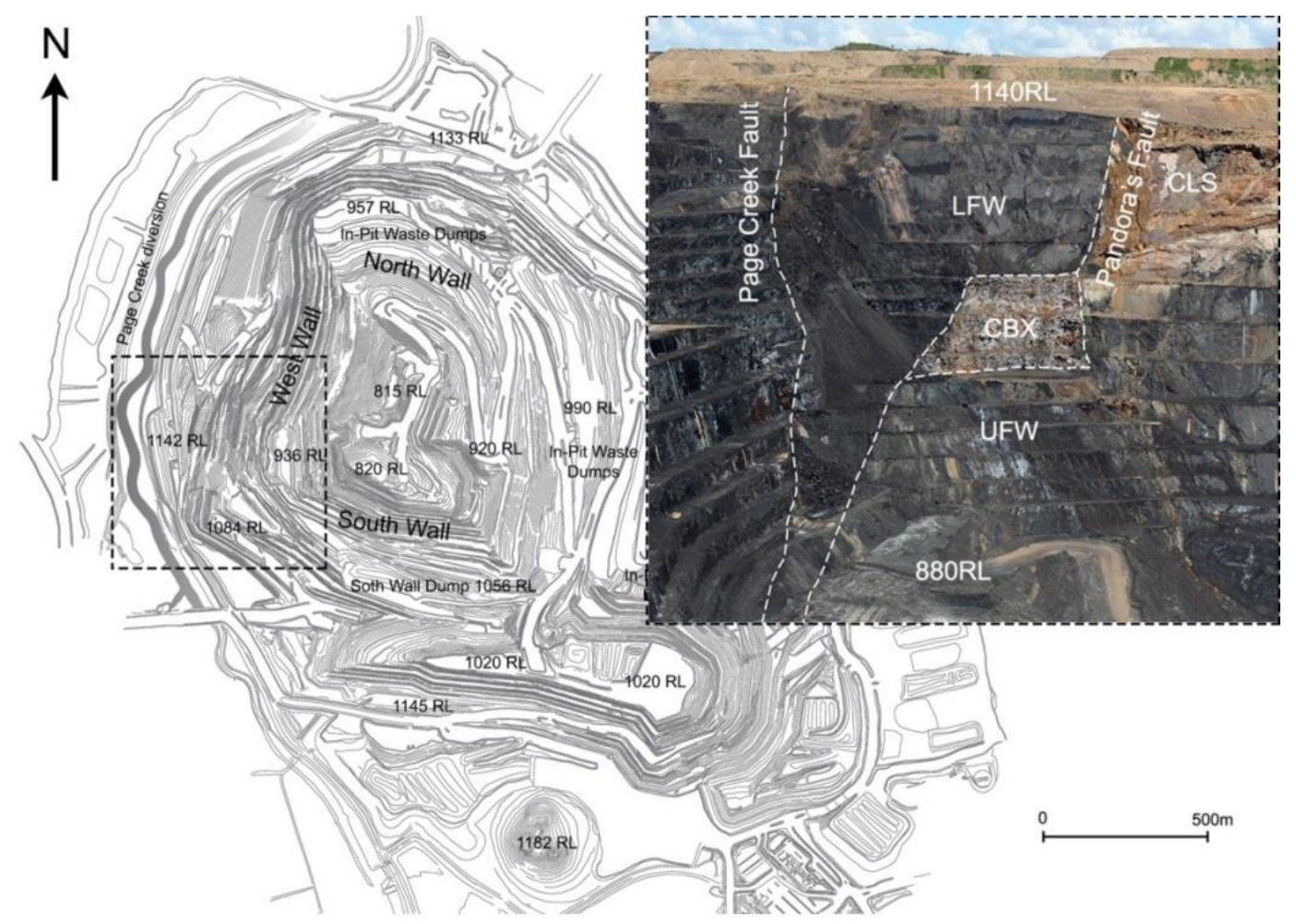

Figure 1 Century mine plane at March 2015 and overview of the SW Wall geotechnical domains and geological structures

Generally, the pit wall experienced periods of rapid acceleration (up to $10 \mathrm{~mm} /$ day) during the wet season and steady trend movements (less than $1 \mathrm{~mm} /$ day) during the dry season (Figures 2(a) and 2(b)). By the end of 2012, an unexpected massive block of carbonate breccia (CBX), extending over five benches was fully exposed along Pandora's Fault. Waltho and Andrews (1993) found the presence of discordant veins of breccia along pre-existing fractures/faults is not unusual at Century, with widths varying from 0.1 to $34 \mathrm{~m}$, although this was the first exposure of this size that had been observed.

Major concerns at the mine started to rise during the 2012-13 wet season, with an increase of acceleration trend and the development of tension cracks up to $30 \mathrm{~m}$ behind the pit crest. A buttress at the toe of the slope $\left(\sim 28^{\circ}\right)$ was recommended by Century to manage the observed progressive movement in the slope above the CBX block. In order to assess the performance of the buttress as a stabilising measure, Itasca conducted a three-dimensional (3D) numerical analysis with Itasca's FLAC ${ }^{3 D}$ (Sainsbury et al. 2013). The possible case scenarios are shown in Figure $2 \mathrm{c}$. The model highlighted how a failure was most likely to occur along Pandora's Fault through the buttress. Moreover, the instability could result in a deep seated failure mechanism, unravelling along Page Creek Fault and then extending along Pandora's Fault.

Due to the instability, access to the wall was limited for the installation of traditional subsurface monitoring. Therefore, MMG management decided to install a microseismic system. The aim of the project was to provide early warning of the development of the deep seated failure and to understand how deep into the wall the rock mass was being damaged. The Australian Centre for Geomechanics was engaged to conduct the research. 

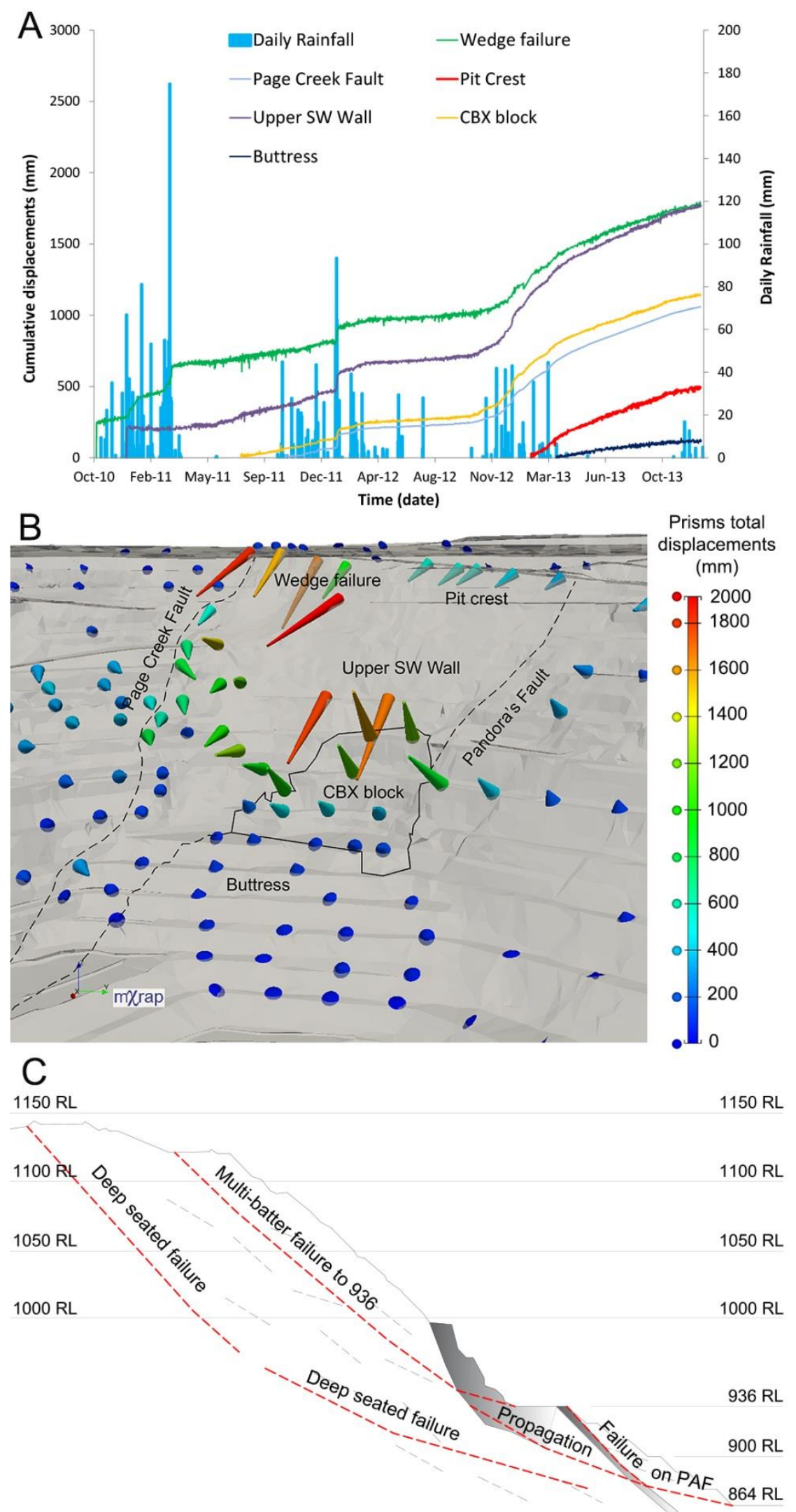

Figure 2 Overview of the instability areas of the SW Wall. a) Ground displacements recorded by the prism monitoring and daily rainfall between October 2010 and January 2014 in different areas of the slope; b) 3D view showing the displacement vectors for the same time period and coloured by total cumulative displacement; c) Possible case scenarios and failure mechanisms based on 2013 studies and numerical modelling (from Salvoni \& Dight 2016) 


\section{$2 \quad$ Microseismic monitoring system}

The microseismic array comprised of 16 sensors located in the volume of rock behind the southwest wall. As shown in Figure 3, the system tends to follow the slope curvature, as pit geometry and accessibility represent major constraints for installing the sensors. Navi-drilled boreholes behind the pit crest were the only option to get the instruments sufficiently close to the instability area. A combination of five $28 \mathrm{~Hz}$ triaxial, six $14 \mathrm{~Hz}$ uniaxial and three $14 \mathrm{~Hz}$ triaxial geophones were placed into four long-inclined (approximately $400 \mathrm{~m}$ ) boreholes. Sensors were installed approximately every $100 \mathrm{~m}$ in each hole, with two sensors at each depth for the purpose of redundancy. Since $4.5 \mathrm{~Hz}$ uniaxial geophones could not be installed in a hole with more than a $2^{\circ}$ deviation from the vertical, two short vertical boreholes (approximately $10 \mathrm{~m}$ ) were drilled near the surface. The distance of the sensors from the surface is $100 \mathrm{~m}$ for the central boreholes and $50 \mathrm{~m}$ for the later one. Sensors S4 and S16 are only $15 \mathrm{~m}$ from the pit face.
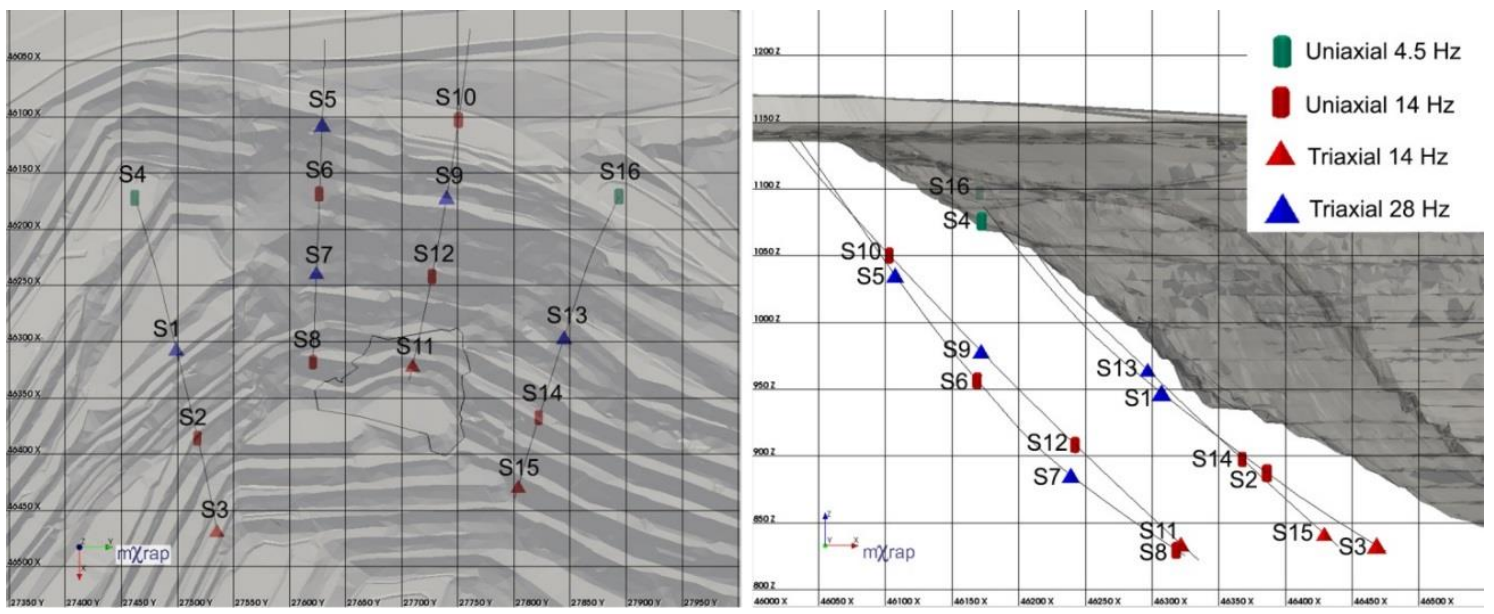

Figure 3 Plan and section view of the microseismic array configuration showing location and type of geophones installed

Seismic signals were sampled at a rate of $6,000 \mathrm{~Hz}$ and a standard trigger algorithm, based on short-time averages (STA) and long-time averages (LTA) of the incoming signal, was deployed. The length of STA and LTA was set at 2.6 and $21.3 \mathrm{~s}$, respectively. A single station was considered to have triggered when STA/LTA was bigger than 12. It is important to highlight how only waveforms from geophones, which exceed the trigger level, were actually recorded. For research purposes only, data was also recorded in continuous mode. The system was fully operative for the end of November 2013 to the middle of April 2014, when stations S13, S14, S16 went offline. At February 2016, when the system was decommissioned, only sensors in the central boreholes were effectively recording.

\section{4 instability reactivation}

During the 2013-14 raining season, the instability of the South-West all started to experience a rapid acceleration of surface deformations with accumulative displacements recorded, from prisms and radar, up to several metres. After several days of rainfall, from the 15 February 2014, a reactivation of movements in proximity of the wedge failure, in the upper section of the pit wall and in the CBX, were observed. On the 23 February, surface movement began to dramatically increase, reaching a peak of $254 \mathrm{~mm} /$ day from mid-March to mid-April. At the same time, a localised failure ( $10 \mathrm{~m}$ depth) occurred in the lower section of Page Creek Fault (Figure 4(a)). 

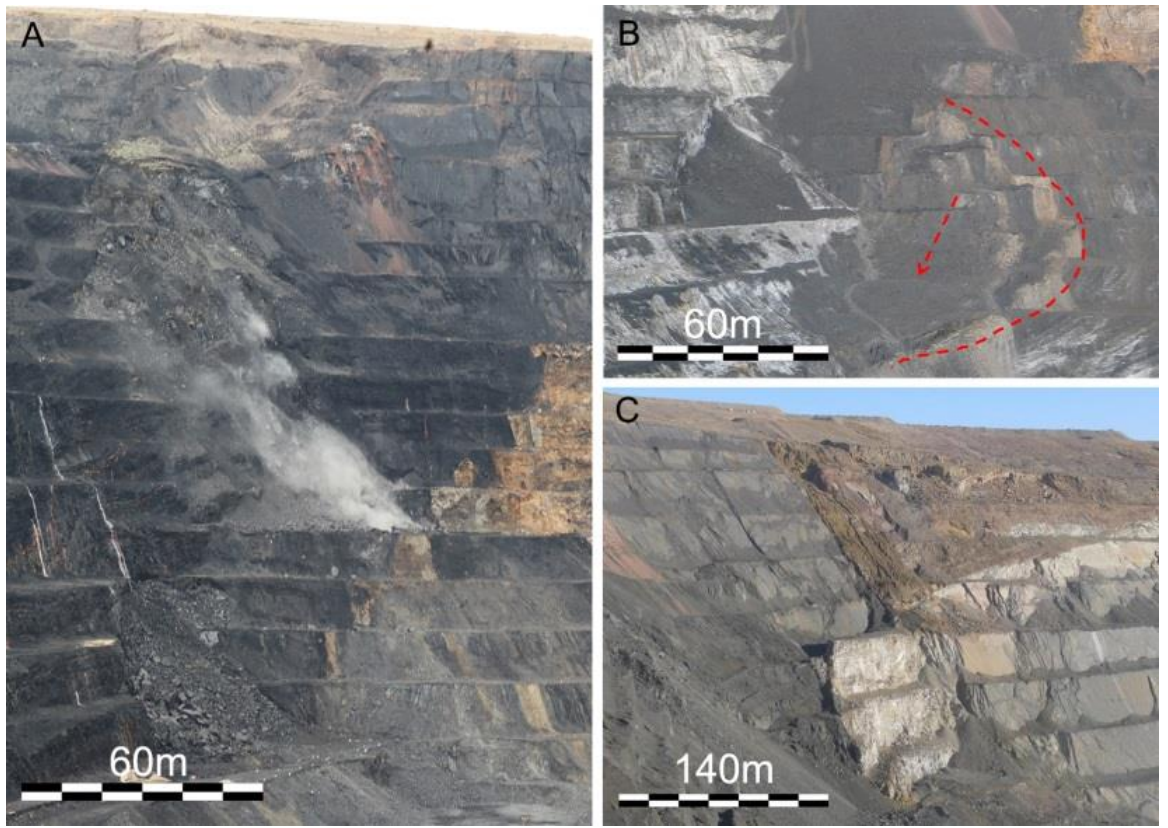

Figure 4 February to May 2014 instability reactivation; (a) localised failure along the lower section of Page Creek Fault; (b) shallow slip zone in the buttress; and, (c) CBX block active passive wedge mechanism, with rotation and consequent detachment (from Salvoni \& Dight 2016)

The buttress area remained stable, except for a shallow slip zone determined by the intersection between Pandora's Fault and a thin weak layer (Figure 4(b)). New tensile cracks also opened up behind the pit crest. It appeared that movements were reduced by the presence of the CBX block, which was acting as a natural buttress whilst slowly being pushed out in a toppling or rotation manner (i.e. active passive wedge), (Salvoni \& Dight 2016). With the progressive rotation of the CBX, fractures were detected behind the block, followed by its partial detachment from the wall (Figure 4(c)). Lipping (differential displacement) was also observed in the right corner at the base of the CBX block. From mid-April 2014, slope deformations gradually decreased, reaching a steady rate of $15 \mathrm{~mm} /$ day in July 2014.

\section{Data analysis comparison}

As previously mentioned, seismic data in the form of seismograms were given to four different groups, which independently analysed the waveforms and provided their own source locations and parameters. All of the groups also had access to the calibration blast result, which was conducted by MMG in order to establish a P-wave and S-wave velocity model. In this paper, we only consider data between 1 February 2014 and 8 April 2014, as this is the only time all groups involved had overlapping results.

From this study and handling of the seismic data, three main methodologies for processing seismic waveforms seem viable for microseismic slope monitoring. These are:

- Real-time processing: this method involves the processing being founded on real-time association between sensors based on a LTA/STA ratio. Generally with this method fewer events are recorded as fewer sensors are available for processing due to the process being automated. The positive of this method is that events can be processed and reported to the mine site in a very short turnover time.

- Continuous-data processing: this method relies on the continuous recording of vibrations at each sensor. Post association is completed based on a LTA/STA ratio and human interpretation. Additionally, when four or more sensors are triggered, the other sensors can be evaluated for event triggers which might not have been above the LTA/STA threshold, therefore, increasing the number of sensors used. Thus, one is able to produce many more events than the real-time processing method. However, because of how more involved this process is, events can only be provided a considerable time after its occurrence. 
- Trigger monitoring: this philosophy assumes the events which are considered vital will occur within the vicinity of the installed sensors and therefore location is not as vital component compared to the rate and size of events. The rate is determined by the number of associated triggers and the size of the event is assumed to be related to the number of sensors associated to the event. This method gives a real-time indication of the activity of fracture occurrence in the rock mass.

The four groups only considered methodology one and two. The details of the approaches for the different groups will be discussed in detail below.

\subsection{Group A}

The first group implemented routine real-time micro-seismic monitoring, based on triggered data recorded according to the scheme discussed in Section 2. The calibration blast test available was used to establish a homogenous and isotropic velocity model, with a $V_{P}$ of $3,674 \mathrm{~m} / \mathrm{s}$ and $V_{S}$ of $2,046 \mathrm{~m} / \mathrm{s}$. Due to the high planarity of the seismic array, the measured direction of the P-wave was also implemented into the location minimisation problem. In fact, location based only on arrival times could lead to two possible locations, one on either side of the common plane of sensors. A seismic sensor will have the same distance to each possible location, making the two locations equally likely in terms of travel times. Therefore, this can create an artefact in location accuracy and artificial alignment distributions of the seismic events (Meyer 2015). The geometry of the pit and the effect of voids on the ray path were not taken into account in this model. Back calculation of the blast locations using this model indicated an average error of $15 \mathrm{~m}$ in the location algorithm. This methodology is mainly based on the underground mining environment experience and it is discussed in detail in Mendecki et al. (2010). This method allows a quick response, with data manually processed $24 / 7$ and made available for the engineers on site in almost all cases within 10 minutes.

In the time window considered, 1,161 events were totally located (Figure 5). Of those, approximately 5\% were recorded below the lowest part of the current pit (880RL) and they were most likely the result of stress changes related to the removal of broken rock after blasting and excavation (Lynch et al. 2005). The analysis of the microseismic data revealed a strong relationship between the temporal and spatial style of activity for different areas of the slope, in the response to the triggering input (rainfall events), (Salvoni \& Dight 2016). Events in the pit wall area were recorded from the 15 February 2014, mainly behind the CBX block. Suddenly, a spike in the seismic activity was recorded on the 23 February around the lower section of Page Creek Fault, where the localised planar failure occurred. In response to the global reactivation of the instability, events were observed in the wedge failure area, in the upper section of the pit wall and behind the CBX block. Despite the shallow slip in the buttress, no seismic activity was recorded in this area.
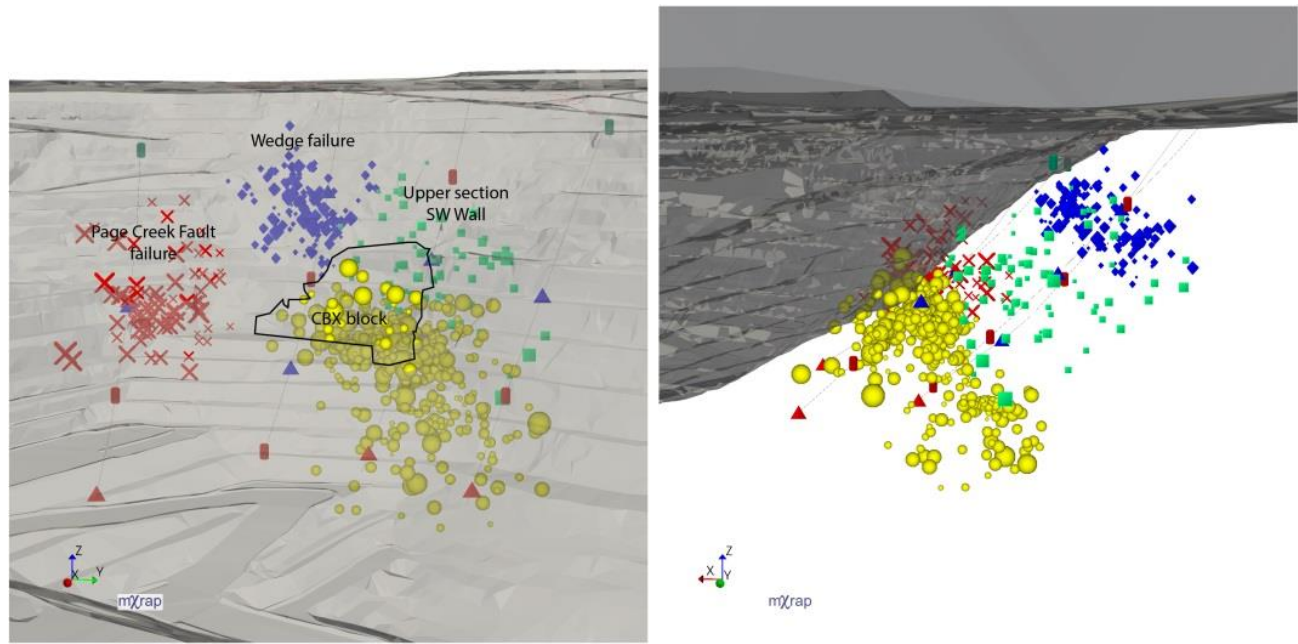

Figure 5 Seismic events processed by Group A; events marker styles are based on spatial occurrence and sized by log(energy) 
Based on the above observations, the following conclusions can be made:

- There is no evidence that failure along Pandora's Fault, through the buttress and a deep seated failure along Page Creek Fault, is actually occurring.

- Seismic activity is well correlated with the spatial and temporal distribution of the areas of instability, except for the shallow slip area.

- The shape of the distribution of seismic events behind the CBX block may indicate that some shearing structure is developing in order to accommodate the progressive rotation of the block. However, as a similar distribution can also be observed in the wedge failure area, the possibility that this may be still related to an array configuration artefact cannot be excluded.

- Only a few poorly clustered events were observed in the upper section of the wall above the CBX. This can be related to the fact that there is a disconnection between deformation at surface and at depth. As discussed in Salvoni and Dight (2016), the large deformations experienced on the wall may be caused by a shallow failure moving by creeping and attributed to progressive weathered shales. The seismicity recorded would then be related to a deeper possible failure, still in development. However, it can also be that the rock mass was already damaged before the installation of the system and therefore be aseismic.

\subsection{Group B}

The second group used both the triggered and continuous databases. A more detailed investigation on the calibration blast test established that the seismic velocity changes between the rock volume to the south and north of Pandora's Fault. For this reason, a 3D velocity model was built to accurately calculate the travel time. South of Pandora's Fault the $V_{P}$ was found to be $3,700 \mathrm{~m} / \mathrm{s}$ and $V_{S} 1,960 \mathrm{~m} / \mathrm{s}$, while north of Pandora's Fault the $V_{P}$ was $2,900 \mathrm{~m} / \mathrm{s}$ and $V_{S} 1,550 \mathrm{~m} / \mathrm{s}$. Pit geometry was not taken into account by this group, but a constraint method was applied to the event location in order to avoid an event to be located in the air off the pit or above the ground surface. Sensor orientation was considered sufficiently reliable by this group and was not taken into account. The location of the blast based on this velocity model and the location algorithm came within $6 \mathrm{~m}$ from where the calibration blast was located.

For each event located by Group A, the continuous database was analysed in order to verify for which geophones there was a reliable $\mathrm{P}$ and $\mathrm{S}$ arrival. It was found that many useful seismic signals found in the continuous data were missed in the triggered data set. This suggested that the trigger (LTA/STA ratio) level was set too high. On average, Group A used only four geophones to locate the events, while Group B used up to seven sensors. Furthermore, Group A only considered events with at least four triggers, Group B investigated events with less than four triggers and investigated the continuous data to see if these events could be located. An extra 218 events were processed by Group B using this technique.

Despite the general distribution of seismic events (Figure 6), the overall clustering, and hence interpretation, did not change much between Group A and B. The following observations can be made:

- Using the continuous data allowed the use of more sensors to locate seismic events; hence one would assume better location accuracy was achieved.

- More events were detected compared to Group A.

- Group B was able to identify an additional cluster close to the shallow slip failure in the buttress.

- Looking at the distribution of seismic events it became evident how, if sensor orientation is not taken into account, location artefacts are created.

- Even from Group B there is no evidence that the failure is going to develop according to 2013 numerical modelling. However, not enough information can be obtained to evaluate the multi-batter failure type one in Figure 3. 


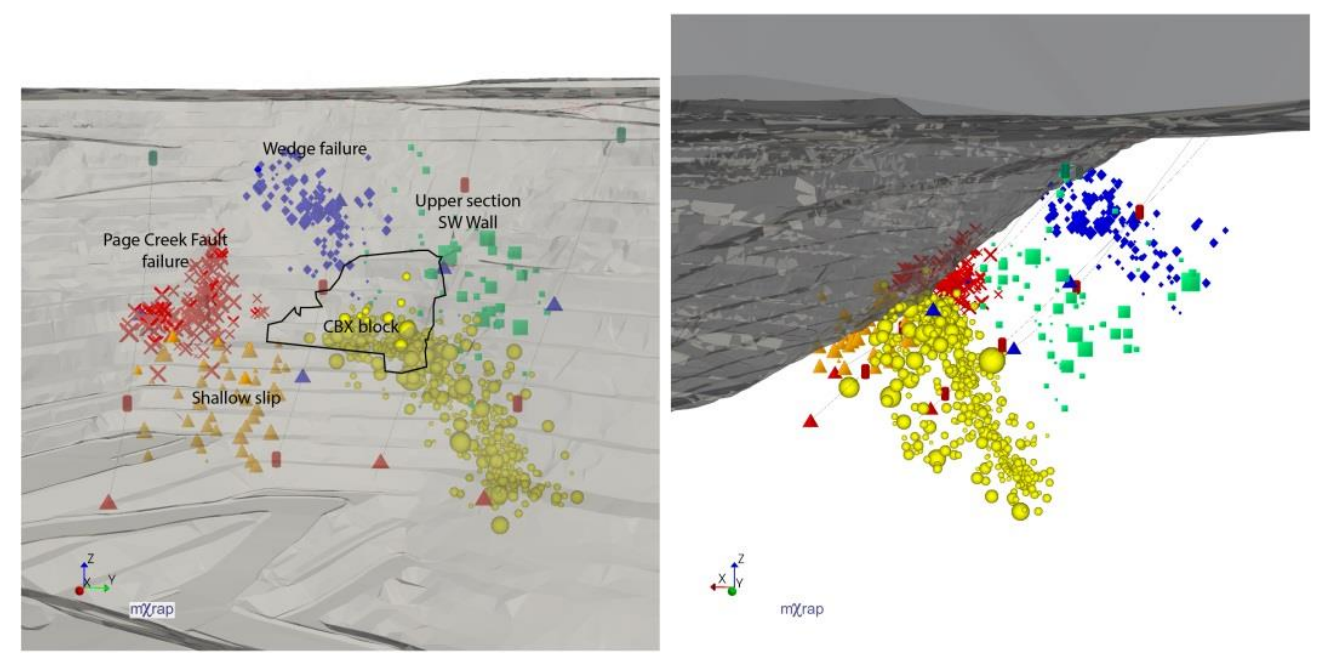

Figure 6 Seismic events processed by Group B; events marker styles are based on spatial occurrence and sized by log(energy)

\subsection{Group C}

The third group reprocessed the data from Group A using the same location algorithm and software. The main difference was that the triggered data was used as a guide to look into the continuous database and locate the events. In this case more than 400 extra events were found during the analysis (Figure 7). The most important highlights were:

- Continuous data allowed recording more events and used more sensors to locate each single event.

- The alignment of events dipping back into the slope disappeared for the cluster in the wedge failure, while in the CBX block they were only reduced.

- A new cluster of events appear in correspondence of the lipping observed in the right corner at the base of CBX block.

- Seismicity tends to be concentrated within a narrow band between 20 and $40 \mathrm{~m}$ from the surface and behind the CBX block. Particularly interesting, is the reduction of seismic activity in the lower section of the wall near the surface. A similar characteristic was also observed in another section view along the wedge failure sector (Figure 8).

- This distribution can be interpreted to be a result of a different instability mechanism between the surface and at depth. The surface monitoring shows a large amount of ground surface displacement. The material, close to the surface, is characterised by intensely broken/weathered rock mass and is no longer able to produce and propagate much seismic energy (i.e. it is an aseismic zone). This area is subjected to creep driven movements that are always present even in dry conditions and characterised by an acceleration in movement related to seasonal rainfall. Unfortunately, the depth of this zone is hard to assess as no sub-surface instrumentation such as inclinometers or extensometers are available and the seismic location accuracy does not allow for this type of resolution. Examples in the literature reported how the thickness of weathered shale layer may reach 9-13 m (Franklin 1981).

- This shallow instability has caused the rotation of the CBX block and triggered further deformation at depth, where between 20 and $40 \mathrm{~m}$ of shearing and rock mass damage is developing into a multi-batter failure. Seismicity behind the CBX block is then related to the creation of an active-passive wedge type mechanism. This type of mechanism seems to reduce during the dry season and be more active during rainfall events. There is no indication of the 
development of a deep seated failure and the extension of the movements into the lower section of the wall.
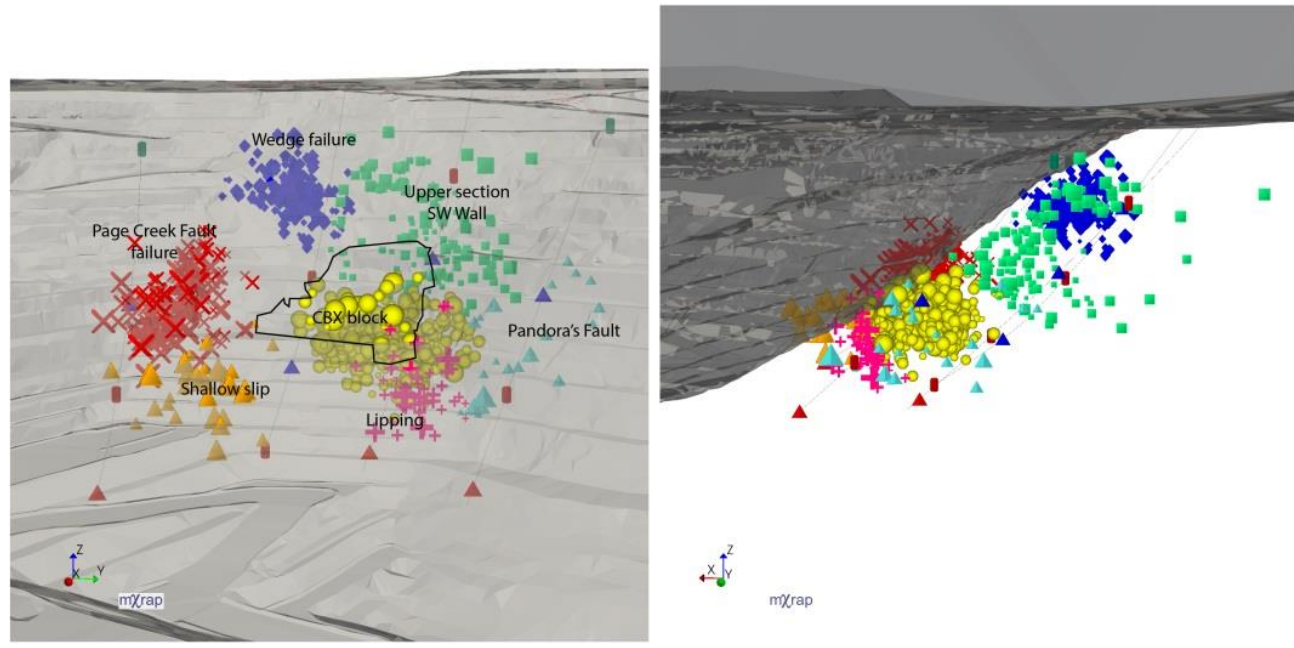

Figure 7 Seismic events processed by Group C; events marker styles are based on spatial occurrence and sized by log(energy)
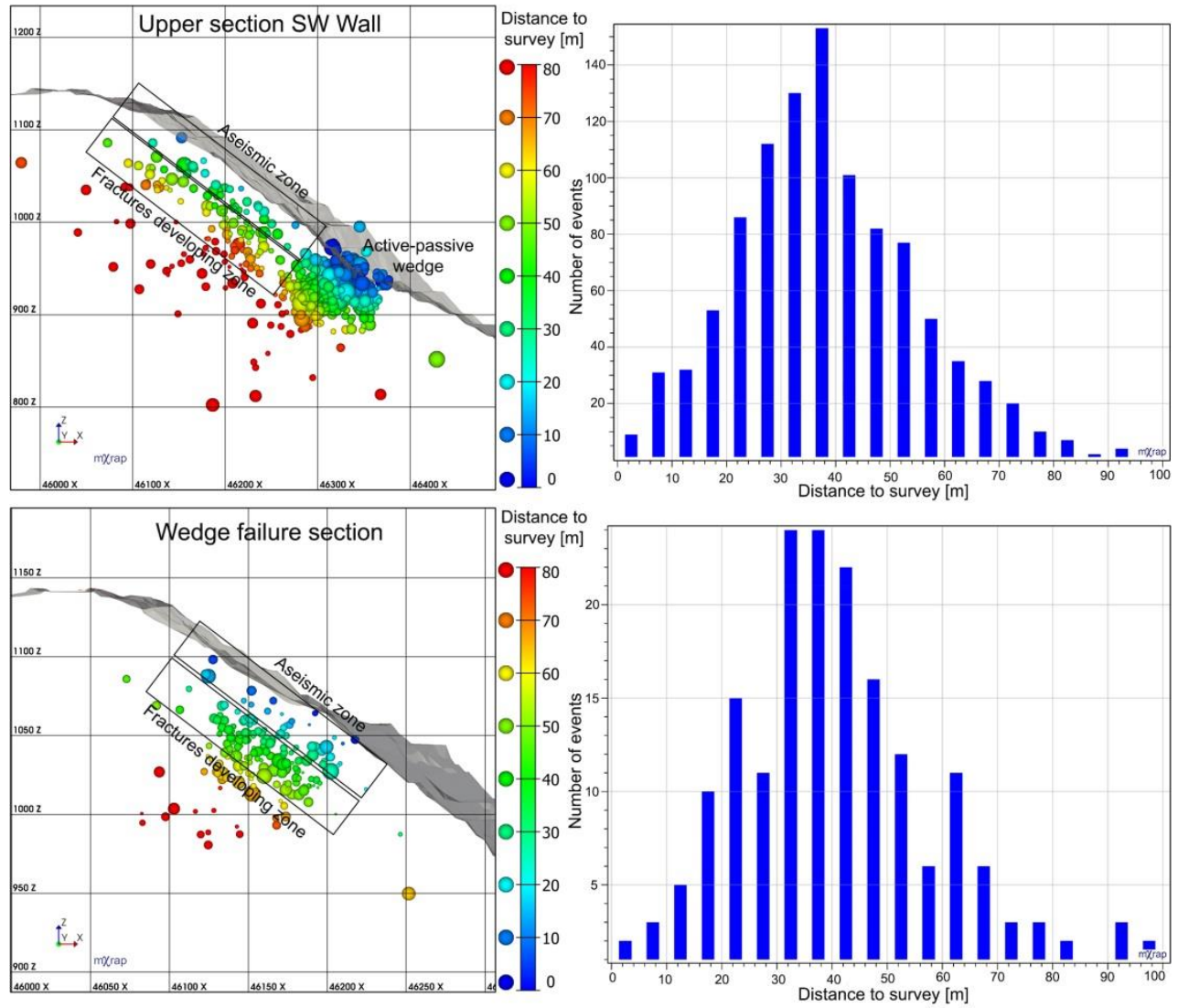

Figure 8 Section through the upper section of wall, CBX block and buttress (above); and, (b) through the wedge failure area (below), showing events coloured by distance to the survey and graph showing the distribution

\subsection{Group D}

The last group used only the continuous data and retriggered those using a STA/LTA ratio of three. Based on the calibration blast a 3D velocity model was used, incorporating the effect of pit geometry to the ray path. This group estimated that the $V_{p}$ and $V_{s}$ were 3,620 and 1,940 m/s, respectively. Initial back 
calculation of calibration blast location using a simple isotropic velocity model gave an average error was $26 \mathrm{~m}$. However, the model was then further refined in order to take into account the effect of pit geometry on the seismic ray-path (Trifu \& Shumila 2010), bringing down the average error to $9 \mathrm{~m}$. Moreover, an attempt to introduce the effect on anisotropic effect was done. This was done by chancing the original velocity normal and vertical to the bedding. In fact, at laboratory scale it was found that $\mathrm{P}$-wave in the two directions differs by $10 \%$. However, relocation of blasting gave less accuracy and therefore only the previous model was used for the processing of the events. Events were automatically processed and then manually checked for quality control.

Below are the main findings based on the seismic data for Group D:

- The number of events located increased sixfold, with a total number of approximately 6,000 . Only $5 \%$ of the seismicity was observed at the bottom of the pit, while the majority was located behind the pit wall.

- General distribution of seismic events did not change compared to the previous databases (Figure 9). However, more seismic events were identified in the shallow portion of the buttress (within 5-10 m) as well as in the right corner of the CBX block (lipping zone).

- A higher number of seismic events were recorded in the upper section of the pit wall and small events were also recorded close to the surface. Distribution of the events in the sections for the main body of the wall and in the wedge failure area is shown in Figure 10.

- As for Group C interpretation the alignment of seismic events for the wedge failure disappeared, while it remained for the CBX block.

- This database helped to further constrain the failure zone and update our interpretation; in particular, it seems that most of the seismicity for the critical area is concentrated in a band within $10 \mathrm{~m}$ from the surface. Therefore, this area is not aseismic. The continuous data means an improvement in the number of events recorded, and hence events were picked that were located here. Some seismicity is observed also at depth that could coincide with type one failure in the model but there are no indications that this has fully developed yet.

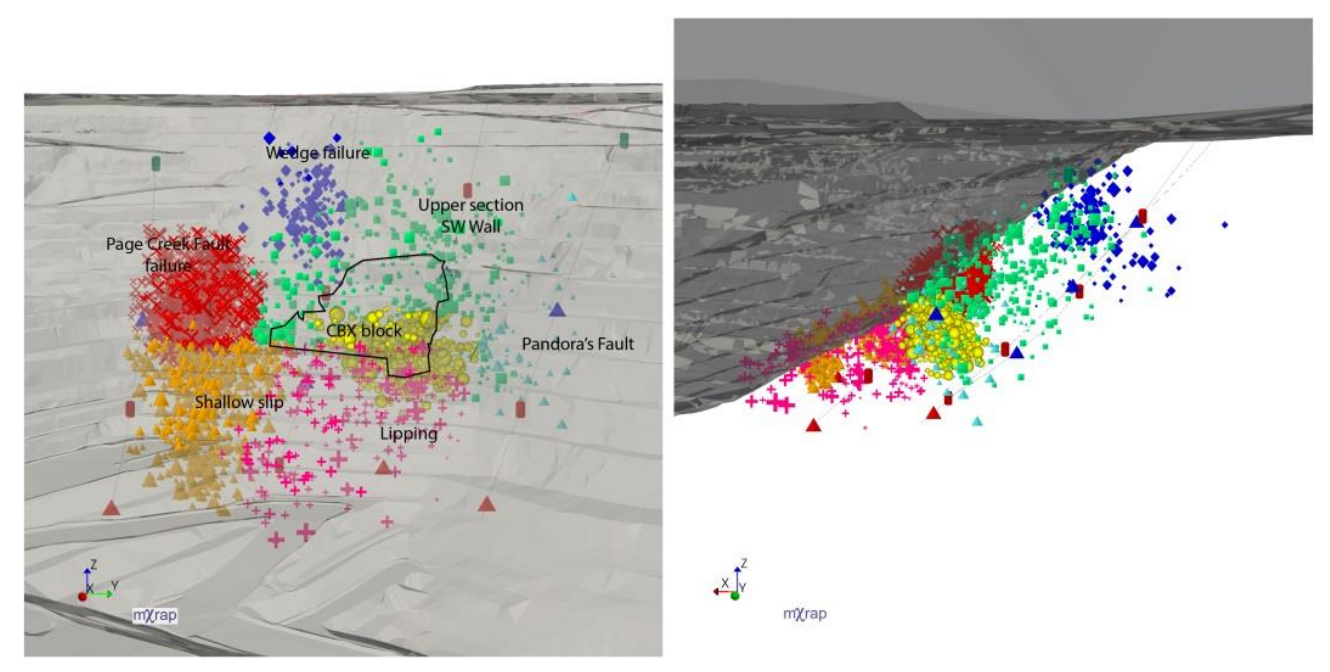

Figure 9 Seismic events processed by Group D; events marker styles are coloured based on spatial occurrence and sized by log(energy) 

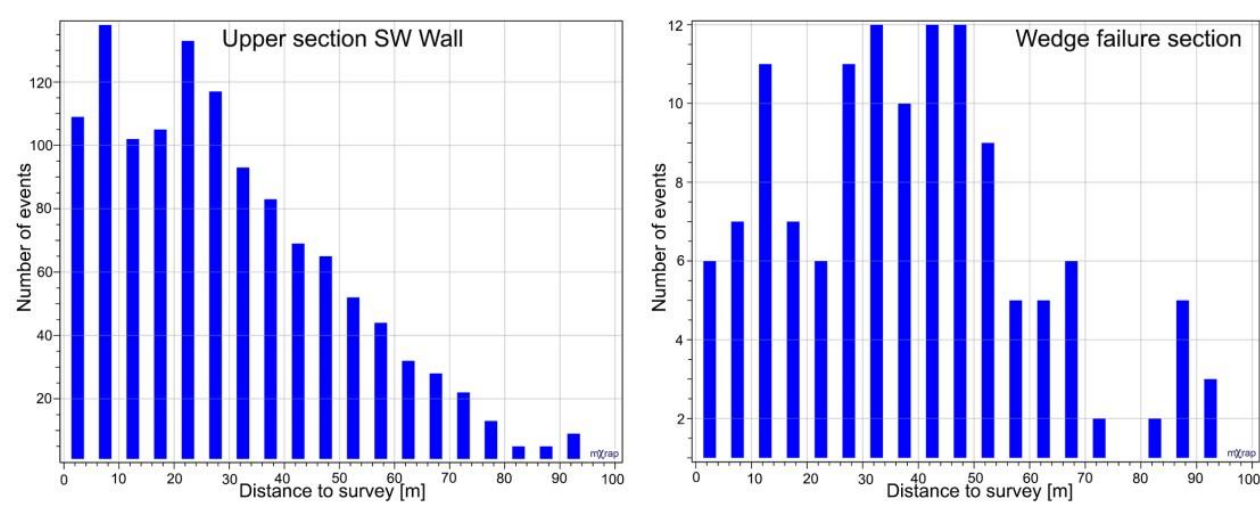

Figure 10 Distribution of seismic events from the surface for the upper section of wall and for the wedge failure area

\section{$5 \quad$ Guideline for microseismic monitoring in open pit mines}

The Century project installed the microseismic system with the aim of monitoring the formation of deep seated failure in the slope. The system was installed with directional holes, and was designed with regards to the best 3D configuration possible. The system also had the ability to measure the sensor-responses continuously. This is something which has not been attempted yet in slope monitoring for mining. The installation and use of a microseismic monitoring system in open pit mines for slope monitoring is not a common practice. Several previous studies (Hudyma et al. 2003; Lynch et al. 2005; Wesseloo \& Sweby 2008; Kagan et al. 2013; Vinoth \& Kumar 2014) discuss details of their seismic system, however, do not give much detail about the design of such a system from scratch. This section will focus on the design methodology for a microseismic system for open pit slope monitoring.

\subsection{Seismic processing approach}

When designing any monitoring system, it is vital to be aware of the aims of the system in question. This includes keeping in mind the other monitoring tools at the disposal of the engineer. For the case of Century mine the aim was to monitor the deep seated failure. Surface displacement was monitored via radar and prisms.

Mendecki et al. (2010) suggest that an underground mine should install a microseismic system to monitor seismicity with the following objectives in mind:

- Rescue: detect and locate potentially damaging seismic events with the aim to assist in rescue operations.

- Prevention: the continuous input of seismic parameters to confirm and correct assumptions made in the design of the mine.

- Seismic hazard rating: to quantify the seismic hazard for use in mitigating seismic risk.

- Alerts: to detect strong changes in seismic spatial and temporal behaviour that might indicate rock mass instability.

- Back analysis: to improve the understanding of the rock mass behaviour with the aim of optimising both the design and monitoring system.

In underground mines all of these objectives are critical to ensure a safe mining environment. However, in the case of open pit mines some of these objectives are less important. For our study the main aim was the understanding and prevention of deep seated failure. Hence the rescue and seismic hazard rating objectives added no value in mitigating the risk on site. The main aims were the back-analyses and prevention objectives, with the alerts of a possible spin-off from the system but which is mostly covered by the installation of a radar and prism system. 
Therefore, the aim was to get as much data as possible, within moderate time frames. There was not much need for knowing the location and source parameters of events within a few minutes or hours. The time intervals at which seismic events needed to be processed, in this case, seemed to be for a few weeks to months. For other mine sites this might differ, it depends on the specific needs and other ongoing monitoring data available.

In hindsight, we suggest the approach presented in Figure 11 for the processing of seismic data in the open pit environment. The trigger data for the seismic data is considered to be the indicator of unusual spatial temporal behaviour. Although events are not located in the pit environment, seismic networks are very sensitive and events are small and therefore, it is a safe to assume the events would be located in the vicinity of the seismic network. For such a setup, the trigger rate would act as an indication of seismic activity and the number of triggers an indicator of event size. When predefined thresholds are exceeded, other monitoring data is investigated (radar and prisms) and the seismic data is processed, if required, and fed back into the decision-making loop. Decisions are then made based on the data available to the user. If no trigger levels are exceeded, or such trigger exceedance is understood (rainfall etc.), then the data is processed on a monthly basis and fed back into the back analysis and prevention design loop for optimisation of the design and system.

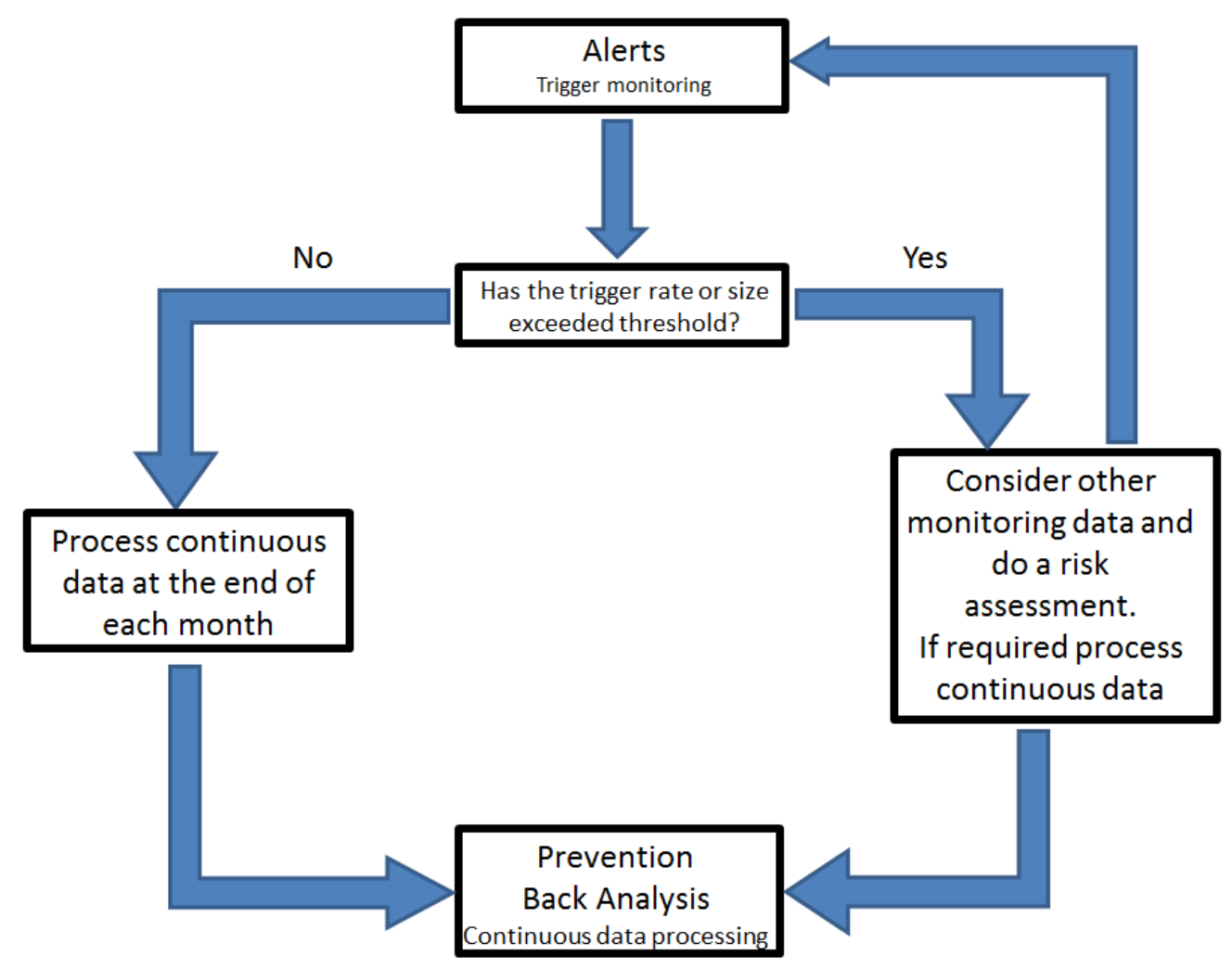

Figure 11 Task action response plan for the processing of seismic data in an open pit mine scenario

The main objective of the system is to get as much data as possible for the least amount of money and time. The approach shown in Figure 11 gives one the best chances to achieve such outcomes. When also considering the costs involved, running multiple approaches, as discussed in Section 4, will be more expensive. Using only triggers has no costs involved, as this is automated, and then paying for processing time every month would be much less per event than for real-time processing.

In Table 1 is a summary of the costs involved for the different processing approaches. As can be seen, the continuous data option is on day-to-day cost comparative to other options (keep in mind Group A is based on a special research price, but is usually more expensive). With regards to cost per event the continuous option is much cheaper. Therefore, it is safe to assume that the continuous data option would be the cheapest option overall. 
Table 1 A summary of the costs involved for each group used for data processing

\begin{tabular}{cccccccc}
\hline Group & $\begin{array}{c}\text { Number } \\
\text { of events }\end{array}$ & $\begin{array}{c}\text { Days of } \\
\text { processing }\end{array}$ & $\begin{array}{c}\text { Total } \\
\text { cost }\end{array}$ & $\begin{array}{c}\text { Normalised } \\
\text { cost per event }\end{array}$ & $\begin{array}{c}\text { Normalised } \\
\text { cost per day }\end{array}$ & Model used & Comments \\
\hline A & 1,966 & 821 & 1.38 & 4.36 & 1.00 & $\begin{array}{c}\text { Real-time } \\
\text { processing }\end{array}$ & $\begin{array}{c}\text { Special } \\
\text { research } \\
\text { price }\end{array}$ \\
\hline B & 1,329 & 66 & 1.00 & 4.65 & 8.99 & $\begin{array}{c}\text { Real-time } \\
\text { improved with }\end{array}$ & Full price \\
\hline continuous & \\
\hline C & 1,594 & 66 & N/A & N/A & N/A & $\begin{array}{c}\text { Real-time } \\
\text { improved with }\end{array}$ & $\begin{array}{c}\text { Internal } \\
\text { company } \\
\text { processing }\end{array}$ \\
\hline continuous & 6,191 & 117 & 1.00 & 1.00 & 5.07 & Continuous & Full price \\
\hline
\end{tabular}

\subsection{Seismic system design}

The design of a microseismic system for an open pit mine depends on several considerations. These considerations would be based on the rock mass properties, stress state, accessibility and event magnitudes under consideration. For an open pit, these considerations will differ from what is traditionally considered for underground mines. The following is a discussion on the differences and considerations taken for the pit design at Century mine.

From a rock mass perspective, several parameters are different to what is seen in underground mines. For Century mine the S-wave velocity was found to be $\sim 2,000 \mathrm{~m} / \mathrm{s}$ and the P-wave velocity as $3,600 \mathrm{~m} / \mathrm{s}$, which is significantly lower than is seen in underground mines. Another significant difference is the attenuation of waves through the rock mass, from this study it seems to be much lower than is generally seen for underground mines. The stress conditions are also much less in this environment, which leads to event frequencies being much lower than one would expect for the underground environment. All these factors must be considered when designing for slope monitoring in an open pit mine. For this paper four main considerations are discussed, which were all considered when designing the microseismic system.

Firstly, designing the best possible 3D configuration for optimal source locations is more difficult in the open pit environment. The sensors can only be installed in an almost planar array, as accessibility is limited by the slope. For Century directional holes were drilled at an expensive cost to get the best possible array. This cost made up the biggest part of the system installation costs. It is unlikely that one would be able to install a better system configuration, yet one still had to use the P-wave directional data for each sensor to ensure the event was located correctly.

The second consideration is the robustness of the system. In the case of Century, two sensors were installed at each station for redundancy. However, when some of the sensors went offline we could not switch to the backup geophones. In fact, as the cable was damaged, the redundancy could not be realised. As the diameter of the hole represents a major constraint for the number of instruments that can be installed, a better idea would have been to reduce the spacing between instruments to $50 \mathrm{~m}$ rather than 100. This would have improved the sensitivity of the array at the same cost.

The third consideration is the attenuation effect for such a shallow system. For Century mine the lamination of the rock mass was considered in processing on several occasions. However, no reliable way could be found to incorporate this into the velocity model. The microseismic network at Century mine was based on what was previously done by Wesseloo and Sweby (2008). Based on their work, and the findings from the Century data, it seems the attenuation can be successfully described using methodology proposed 
by Hardy Jr et al. (1988). They proposed the attenuation effect can be described effectively through the following equation:

$$
\text { Range }=-0.8 \text { Frequency }+C_{\text {attenuation }}
$$

where:

Range is the distance to the fourth sensor.

Frequency refers to the corner frequency of the event.

$C_{\text {attenuation }}$ is a constant describing the attenuation effect (4,000 for open pit slopes, 30,000 for underground hard rock mines).

For underground mines $C_{\text {attenuation }}$ is found to be $\sim 30,000$, while in the case of Century this value is closer to 4,000. In Figure 12 the application of Hardy Jr et al. (1988) is illustrated. Assuming the solution is universally similar for most open pit slope environments, this equation can be used as a rough estimate for planning future microseismic systems.

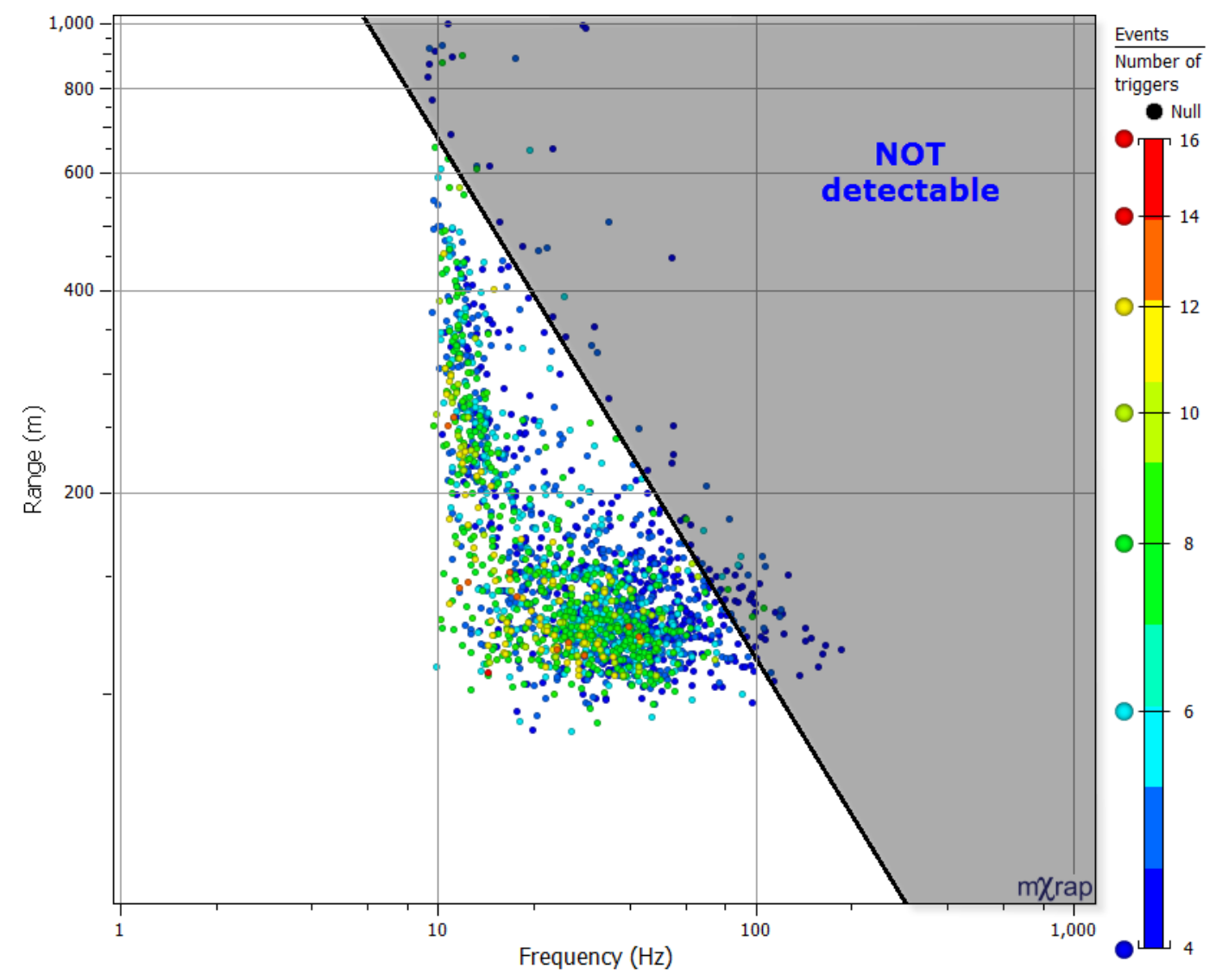

Figure 12 The application of Hardy Jr et al. (1988) for the Century Group C dataset

The last consideration is the choice of sensors used for recording the seismic events. As previously discussed, the events in this environment have much lower frequencies due to the rock mass and stress conditions. For Century mine the static stress drop is $\sim 1-2 \mathrm{KPa}$ which is in line with what was previously seen from other open pit slope monitoring data. Trifu et al. (2005) found static stress drop values at Mount Keith open pit mine to be less than $10 \mathrm{KPa}$. In a typical underground mine, the static stress drop values range from $100 \mathrm{KPa}$ to a few $\mathrm{MPa}$. It is this property which partly drives the lower than expected frequencies seen for open pit mines.

This knowledge was one of the main driving forces for Century mine deciding on installing a combination of 4.5, 14 and $28 \mathrm{~Hz}$ sensors. Figure 13 is an illustration of how these frequency ranges compare to the recorded events. The shaded area shows the frequency domain in which the events would have been 
effectively recorded ( $\mathrm{Mw}$ ranges from -3.4 to -0.2 ). The upper and lower frequency boundaries are based on guidelines from Mendecki (1997). Their findings show events would only be effectively recorded if their frequencies are between two times the lower frequency (for Century $4.5 \mathrm{~Hz}$ ) and the upper frequency (for Century $2,000 \mathrm{~Hz}$ ) divided by five. These boundaries are illustrated by the horizontal dashed lines. The vertical dashed lines indicate the seismic moment based on the accepted frequency ranges. Events in the circle are therefore outside of these ranges and therefore their source parameters cannot be trusted. The diagonal lines indicate the static stress drop values based on an S-wave velocity of 2,000 m/s and a Brune k-value of 1.88 .

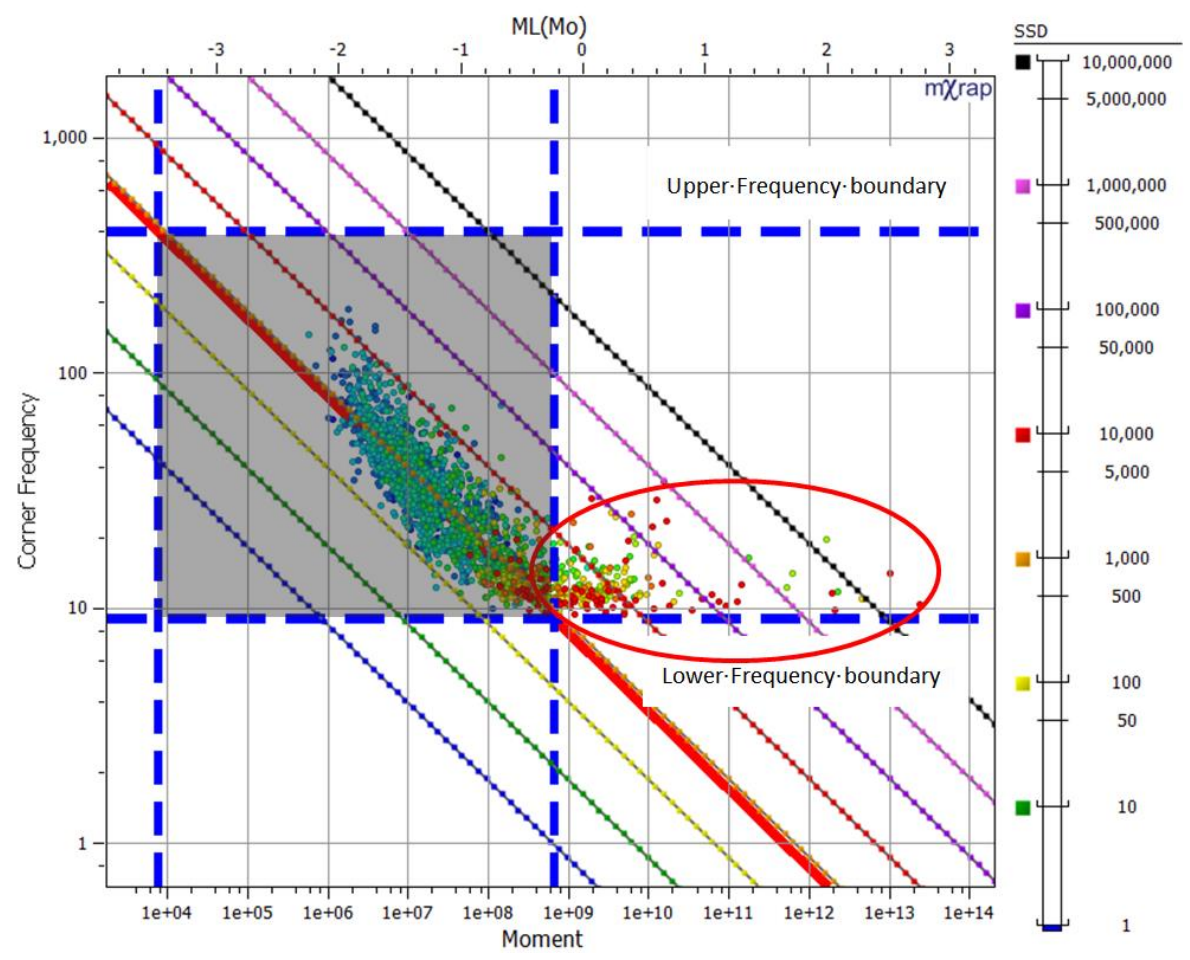

Figure 13 Effect of sensor frequency ranges on the ability to record data accurately. The greyed out area indicates which events could be effectively recorded by the system installed, events outside of this area (circled area) could not be accurately recorded, and any source parameter specific analysis cannot be trusted. The diagonally coloured lines indicate the static stress drop; values for these lines are in the legend

Based on the knowledge gained from the Century project and work from Mendecki (1997), Hardy Jr et al. (1988), Trifu et al. (2005) and Wesseloo and Sweby (2008), the chart shown in Figure 14 is proposed for use in designing microseismic systems for slope monitoring in the open pit environment. The design chart is based on the following parameters:

- Static stress drop $=1 \mathrm{KPa}$.

- Brune k-value $=1.88$

- S-wave velocity of $2,500 \mathrm{~m} / \mathrm{s}$

The design chart in Figure 14 can then be used to determine what the rough ranges are for the system based on the monitoring needs. The chart has several details of importance. The diagonal lines indicate the static stress drop lines, the meaning of the colours are shown by the marker style to the right of the chart. The black diagonal line on the chart at the right bottom, is based on the Hardy Jr et al. (1988) work as was discussed before, and it is an indication of the microseismic system density. The range indicates the distance to the fourth sensor of the array. 


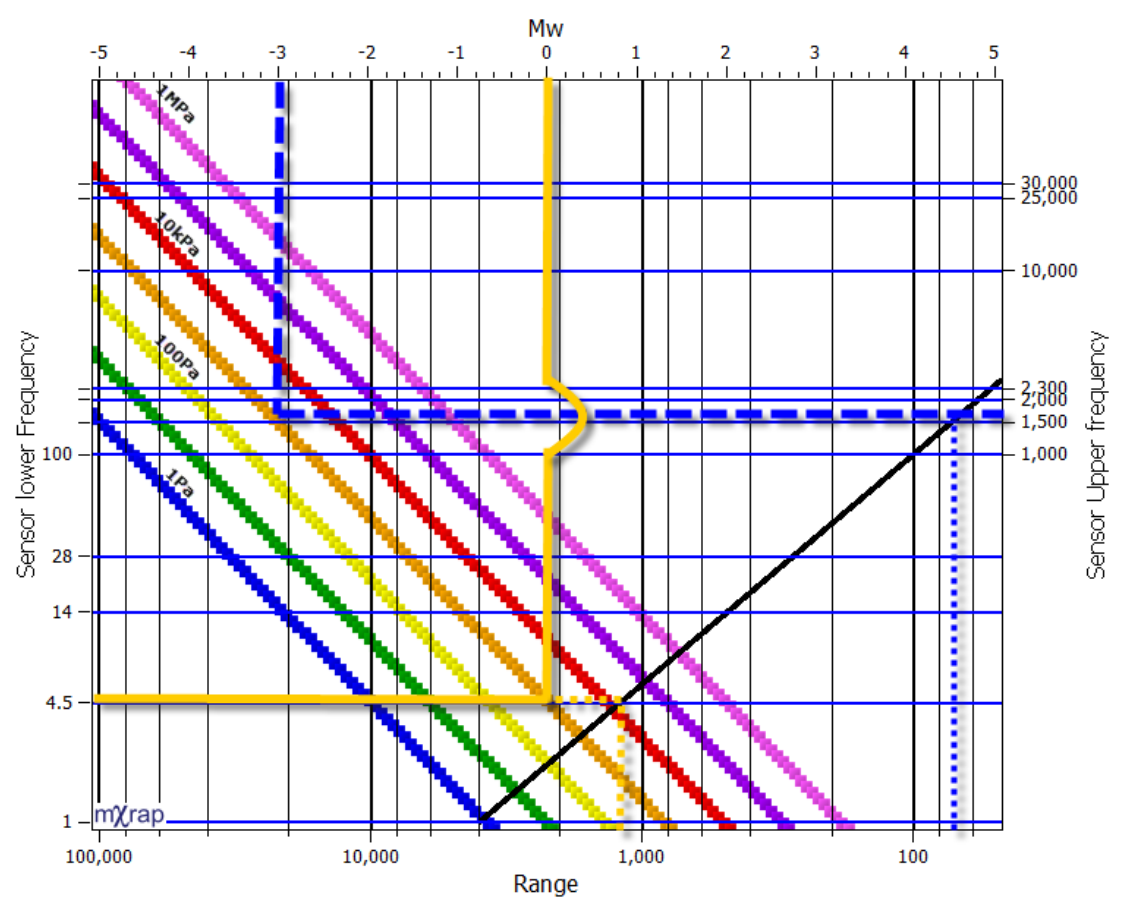

Figure 14 Illustration of how to use the design chart to determine the density and frequency range for the microseismic network. The dashed blue lines is used to describe the upper magnitude limit's properties, while the solid orange lines show the lower magnitude properties

For this design, the aim is to record magnitudes -3 to 0 . To record a magnitude 0 event (illustrated by the solid orange line), a lower frequency of $4.5 \mathrm{~Hz}$ is required. This frequency is determined by vertically drawing a line downwards from magnitude 0 , where it intersects the relevant static stress drop line it is connected horizontally to the lower frequency value. The frequency values on the left axis are the lower ranges of the most common sensors used in the industry. The lower frequency ranges determine the upper magnitude ranges one can record. For the lower magnitude $(-3)$ the dashed blue line is used to indicate which upper frequency range will be required (right axis). In this instance, sensors with an upper frequency of $2,000 \mathrm{~Hz}$ are required. The network density can be found by looking at where the dashed blue and solid orange lines intersect the black line. For the magnitude 0 , the fourth furthest sensor to the event should not be more than $\sim 1,200 \mathrm{~m}$ from it. For the magnitude -3 , this value is closer to $80 \mathrm{~m}$.

The design chart in Figure 14 is meant to be used as a rough estimation of the seismic network properties. It aims to be a guideline for those engineers who do not have the background or experience in microseismic monitoring but need to design such a system. The microseismic system can be optimised when events start to be recorded.

\section{Conclusion}

Based on the evidence of the Century project, some guidelines for microseismic monitoring in open pit mines can be constructed as follows:

- Traditional triggered mode monitoring is not adequate to fully understand the development of a failure and the behaviour of the rock mass at depth for an unstable slope; continuous data should be recorded, at least for a reasonable time period at the beginning of the installation, in order to set the optimum STA/LTA ratio.

- Continuous data equates to more sensors, on average, per event than for real-time monitoring. This means better source locations and parameters.

- Inclusion of the sensor orientation is not negotiable; this is particular evident when only a few sensors are used and the array becomes roughly planar. 
- Instead of using two sensors every $100 \mathrm{~m}$, it is strongly recommended to locate a sensor every $50 \mathrm{~m}$. This would improve the sensitivity or the array. In case of shearing along the borehole case, more sensors for each station do not guarantee a backup.

- Ray tracing and open pit geometry effect can help to further constrain the location accuracy.

- The use of the design methodology, we propose, can be used to design microseismic systems in the open pit environment before knowing the seismic properties of the environment.

- When events are found outside, what is considered good frequency ranges, those events will have source parameters which are not accurate.

\section{Acknowledgement}

The authors are deeply grateful to MMG Limited for funding the project and allowing access and logistic support to the study area; to C Coimbra, C Holland, E Sweeney and K Abbott (MMG's Geotechnical Team) for the collaboration in collecting data in the field and for the useful discussions on geotechnical aspects of the South-West wall. The authors wish to thank to The University of Western Australia and the Australian Centre for Geomechanics for their scholarship contributions during Michele Salvoni's PhD candidature.

\section{References}

Broadbent, GC, Andrews, SJ \& Kelso, IJ 2002, 'A decade of new ideas: geology and exploration history of the Century Zn-Pb-Ag deposit, Northwestern Queensland, Australia', in RJ Goldfarb \& RL Nielson (eds), Integrated methods for discovery: global exploration in the twenty-first century, Society of Economic Geologists, Inc., Special Publication 9, pp. 119-140.

Franklin, JA 1981, 'A shale rating system and tentative applications to shale performance', Transportation Research Record, 790, pp. 2-12.

Hardy Jr, HR, Belesky, RM, Kimble Jr, EJ, Mrugala, M, Hager, ME \& Taioli, F 1988, A study to investigate the potential of the acoustic emission/microseismic technique as a means of evaluating slope stability, Final Report (No. FHWA-PA-87-029+83-35).

Hendersonhall, BD, Lucas, D, Kerr, N \& Pennisi, C 2010, 'Practical Management of Progressive Large Failures at Minerals and Metals Group Century Mine', in Proceedings of the 7th Large Open Pit Mining Conference, The Australasian Institute of Mining and Metallurgy, Melbourne, pp. 15-30.

Hudyma, MR, Jiang, JJ \& Reimnitz, M 2003, 'Seismic monitoring at the Fimiston open pit Kalgoorlie Consolidated Gold Mines (KCGM)', in Proceeding of 5th Open Pit Mining Conference, Australasian Institute of Mining and Metallurgy, Melbourne.

Kagan, MM, Kozyrev, AA \& Chernobrov, DS 2013, 'Results related to pitwall microseismic monitoring ("Zhelezny" Mine, Kovdorsky Gok, JSC)', in A Malovichko \& D Malovichko (eds), Proceedings of the 8th Symposium on Rockbursts and Seismicity in Mines, Saint-Petersburg-Moscow, Russia, pp. 501-504.

Kurukuk, N \& Sweeney, E 2012, 'Slope Stability Assessment at an open pit mine in Northwest Queensland, in Proceedings of the 9th ANZ Young Geotechnical Practitioners Conference (9ANZYGPC), Australian Geomechanics Society, Barton, p. 9.

Lynch, RA, Wuite, R, Smith, BS \& Cichowicz, A, 2005, 'Microseismic monitoring of open pit slopes', in Y Potvin \& M Hudyma (eds), Proceedings of the 6th Symposium on Rockbursts and Seismicity in Mines, Australian Centre for Geomechanics, Perth, pp. 581-592.

Mendecki, AJ, 1997, 'Seismic monitoring in mines', Springer Science \& Business Media.

Mendecki, AJ, Lynch, RA \& Malovichko, DA 2010, 'Routine Micro-Seismic Monitoring in Mines', in Proceedings of the Australian Earthquake Engineering Society 2010 Conference, Perth.

Meyer, S 2015, 'Slope deformation mechanics from microseismic monitoring', in Proceedings of the 2015 International Symposium on Slope Stability in Open Pit Mining and Civil Engineering, SAIMM, pp. 181-193.

Sainsbury, B, Hebert, Y \& Sainsbury, D 2013, 'Assessment of the Long-Term Stability of the Stage 8 West Wall Cutback at MMG Century', Itasca internal report.

Salvoni, M \& Dight, PM 2016, 'Rock damage assessment in a large unstable slope from microseismic monitoring-MMG Century mine (Queensland, Australia) case study', Engineering Geology, vol. 210, pp. 45-56.

Trifu, C, \& Shumila, V 2005, Comparison of Accelerometer and Geophone Recordings of Induced Seismicity at Mt. Keith Open Pit Mine, Western Australia, internal ESG report to Mount Keith.

Trifu, Cl \& Shumila, V, 2010, 'Geometrical and inhomogeneous raypath effects on the characterization of open-pit seismicity', in 44th US Rock Mechanics Symposium and 5th US-Canada Rock Mechanics Symposium 2010, American Rock Mechanics Association.

Vinoth, S \& Kumar, LA 2014, 'Applying real time seismic monitoring technology for slope stability assessment - An Indian opencast coal mine perspective', International Journal of Mining Science and Technology, 24, pp. 75-80.

Waltho, AE \& Andrews, SJ 1993, 'The Century zinc-lead deposit, Northwest Queensland', in IJ Duncan (ed.), Proceedings of the Australasian Institute of Mining and Metallurgy Centenary Conference, Australasian Institute of Mining and Metallurgy, Carlton, pp. 41-61.

Wesseloo, J \& Sweby, G 2008, 'Microseismic monitoring of hard rock mine slopes', in Y Potvin, J Carter, A Dyskin \& R Jeffrey (eds), Proceedings of the First Southern Hemisphere International Rock Mechanics Symposium, Australian Centre for Geomechanics, Perth, pp. 433-450. 
